\title{
Effect of Dynamic Absorber Configuration on the Reduction of Vibration
}

\author{
Martin Orečný*, Štefan Segl'a, Róbert Huňady, L'ubica Miková \\ Department of Applied Mechanics and Mechatronics, Technical University in Košice, Košice, Slovak Republic \\ *Corresponding author: martin.orecny@tuke.sk
}

Received October 13, 2014; Revised October 24, 2014; Accepted November 07, 2014

\begin{abstract}
The article deals with passive suspension system of a seat employing two types of dynamic absorbers. The methodology how to design such a system is explained in the paper. The first type of dynamic absorber is composed by two masses connected to the seat by springs and dampers in parallel configuration. The second one is composed by two sprung masses connected to the seat in the series. The parameters of the seat suspension system and the dynamic absorber parameters were all determined by an optimization process based on genetic algorithms. The objective function for the optimization was to minimize the seats displacements. The vibration reduction of the seat is compared for both investigated cases.
\end{abstract}

Keywords: dynamic absorber, genetic algorithm, vibro-isolation, optimization, evaluation

Cite This Article: Martin Orečný, Štefan Segl'a, Róbert Huňady, and Lubica Miková, "Effect of Dynamic Absorber Configuration on the Reduction of Vibration.” American Journal of Mechanical Engineering, vol. 2, no. 7 (2014): 270-273. doi: 10.12691/ajme-2-7-20.

\section{Introduction}

Vibro-isolation of the seat of a driver or operator is a very important field of study because the transition of vibrations on operators has a very negative effect on their health and can reduce the safe manipulation of the machines. Therefore it is necessary to design a suspension of a seat, which will secure the safe manipulation of the machine and also will hold the right level of the operators' comfort.

The seat suspension is realized by springs, air actuators, and hydraulic dampers, semi active or active dampers. The most common and used are passive seat suspensions, which are installed in buses, trains, working machines in mines and in agricultural machines. Reduction of vibration of passive seat suspension is limited by the properties of spring and damper because they don't change their characteristics like stiffness and damping. The reduction of vibration in this case can be improved by applying dynamic absorbers (DA) on the seat. Segl'a in work [1] proposed a solo dynamic absorber connected to the seat. After the optimization of the suspension parameters he achieved only $7 \%$ improvement because a dynamic absorber (DA) is capable to reduce the vibration only in a narrow frequency range. According to Collete [2] applying a solo DA will reduce the maximal amplitude of displacement in the resonance range. Therefore for reducing vibration in a wider frequency range there is necessary to use more DAs like is shown in work [3]. Their focus was to use more DAs witch frequencies were non-homogeneously distributed. The proposed system had better results compared a system which DAs had the same spring stiffness's and coefficients of damping. Sun in work [4] stated that the reduction of vibration can be even more effective using a semi active dynamic absorber (SADA) and a nonlinear DA. This alternative shows that the system has good vibration reduction in transient and steady vibrations. Eason in work [5] investigated a system with three degrees of freedom that was composed from a linear based system with a DA and a SADA with four order lower weight. It is worth noting that in all these cases the effectivity of the applied DA is dependent from the right choice of the system, the maximal amplitude of the excitation and others. Therefore it is necessary to optimize the system parameters after the tuning of DA $[6,7,8]$. The DA are chosen to work in narrow frequency ranges, therefore the FFT analysis has to be made, or the system parameters and the DA parameters can be set at once using optimization by genetic algorithms with a defined objective function.

\section{Seat Model}

The first investigated type of seat is with the application of two DAs that are parallel to each other, and that are connected to the seat by dampers and springs as it can be seen in Figure 1.

This system has three degrees of freedom. Each mass can move only in the vertical direction.

The equations of motion for the three mass system are as follows

$$
\begin{gathered}
m \ddot{x}+b(\dot{x}-\dot{y})+k(x-y)+b_{1}\left(\dot{x}-\dot{x}_{1}\right) \\
+k_{1}\left(x-x_{1}\right)+b_{2}\left(\dot{x}-\dot{x}_{2}\right)+k_{2}\left(x-x_{2}\right)=0, \\
m_{1} \ddot{x}_{1}-b_{1}\left(\dot{x}-\dot{x}_{1}\right)-k_{1}\left(x-x_{1}\right)=0,
\end{gathered}
$$




$$
m_{2} \ddot{x}_{2}-b_{2}\left(\dot{x}-\dot{x}_{2}\right)-k_{2}\left(x-x_{2}\right)=0 .
$$

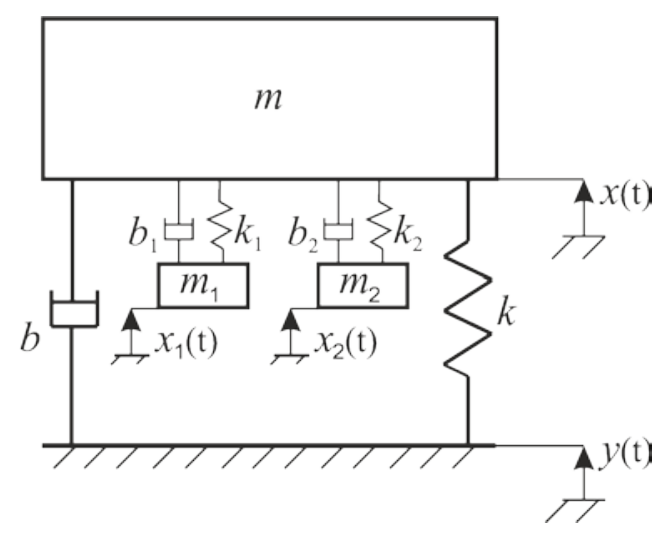

Figure 1. Seat with two Das in parallel

The second investigated system contains two DAs aligned in a series. The system has also three degree of freedom only in the vertical direction as it can be seen in Figure 2.

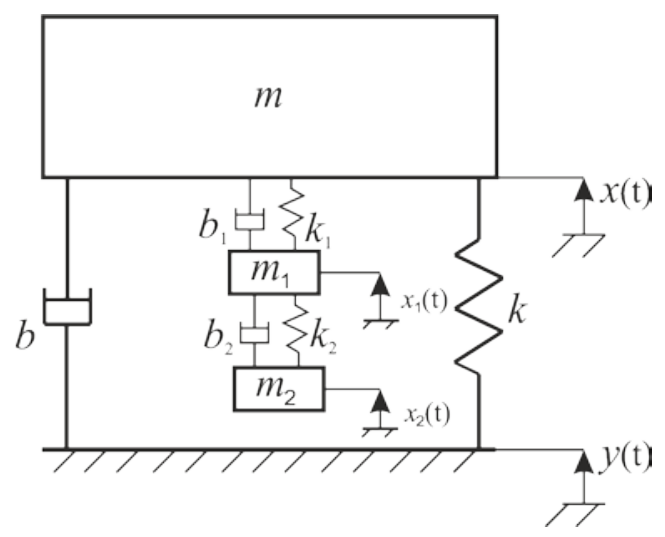

Figure 2. Seat with two DAs in series

The equations of motion are

$$
\begin{gathered}
m \ddot{x}+b(\dot{x}-\dot{y})+k(x-y)+b_{1}\left(\dot{x}-\dot{x}_{1}\right)+k_{1}\left(x-x_{1}\right)=0,(4) \\
\quad m_{1} \ddot{x}_{1}-b_{1}\left(\dot{x}-\dot{x}_{1}\right)-k_{1}\left(x-x_{1}\right) \\
+b_{2}\left(\dot{x}_{1}-\dot{x}_{2}\right)+k_{2}\left(x_{1}-x_{2}\right)=0 \\
m_{2} \ddot{x}_{2}-b_{2}\left(\dot{x}_{1}-\dot{x}_{2}\right)-k_{2}\left(x_{1}-x_{2}\right)=0
\end{gathered}
$$

Where

$b_{\mathrm{i}}$ is the coefficient of damping [Ns/m],

$k_{\mathrm{i}}$ is the spring stiffness $[\mathrm{N} / \mathrm{m}]$,

$m_{\mathrm{i}}$ is the mass [kg],

$y(\mathrm{t})$ is the kinematic excitation [m].

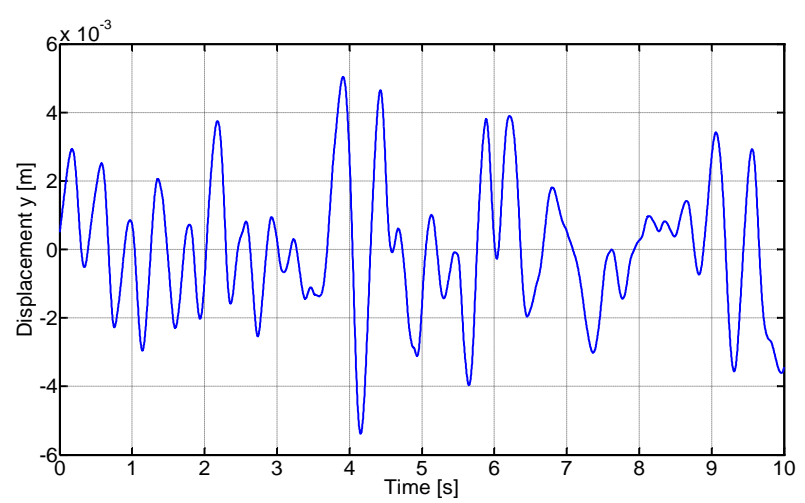

Figure 3. The kinematic excitation $y(\mathrm{t})$ over time
The kinematic excitation was measured in a working machine floor. It was measured in the vertical direction and its time dependence is documented in Figure 3.

For evaluation of the DA parameters in a standard case the Fast Fourier Transformation of the kinematic excitation would be needed. The parameters of the DA would be evaluated based on the frequency with the higher magnitude. The frequency would be chosen from the spectrum and the analytical method can be applied. The frequency spectrum of kinematic excitation $y(t)$ is illustrated in Figure 4.

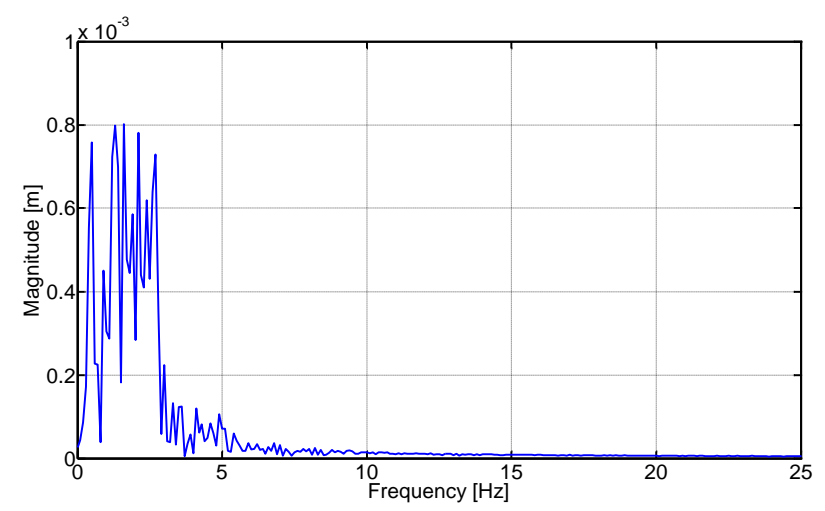

Figure 4. Frequency spectrum of $y(\mathrm{t})$

From Figure 4 it is clear that there are more dominant frequencies in the range from 0 to $4 \mathrm{~Hz}$. To evaluate the stiffness of the spring, the mass of the DA have to be known, or chosen. If the DA also has an applied damper the computation and evaluation and the frequency analysis is complicated and it requires more time. After the DA is tuned to a certain frequency then the parameters of the seat suspension are usually optimized. In this research the parameters of the suspension and the parameters of both DAs will be evaluated using genetic algorithms, therefore no parameters have to be chosen before the evaluation.

\section{Optimization}

The optimization process requires an objective function according to which the parameters will be evaluated. The objective function in this case is the minimization of the seats displacements $x(\mathrm{t})$. The minimization of the seat displacements is required in cases where a high level of control and safe manipulation of the machine is needed. The single criterion objective function can be formulated as

$$
f_{\text {objective }}=\min (x)
$$

\section{Numerical Results}

In the first case the optimization of the parameters was made. After the parameters were evaluated the simulation took place. Genetic algorithm are for solving unconstrained problems, but in this case to reduce the computational time and the values of the searched parameters were positive numbers lower and upper bounds were added. As it was shown by LI in work [3] a higher level of vibration reduction was achieved when the 
DAs were tuned on different frequencies. The resonant frequencies of the DAs were no homogeneously distributed.

Table 1. Suspension parameters of the seat with parallel DAs

\begin{tabular}{|c|c|c|c|}
\hline & \multicolumn{2}{|c|}{ Bounds } & \\
\hline Parameter & Lower & Upper & Result \\
\hline$b$ & 500 & 4000 & 3990 \\
\hline$k$ & 3000 & 9300 & 3910 \\
\hline$m_{1}$ & 3 & 5 & 4,13 \\
\hline$b_{1}$ & 20 & 800 & 260 \\
\hline$k_{1}$ & 500 & 2500 & 2091 \\
\hline$m_{2}$ & 4 & 9 & 8,72 \\
\hline$b_{2}$ & 25 & 1000 & 39,4 \\
\hline$k_{2}$ & 400 & 3000 & 498,5 \\
\hline
\end{tabular}

Therefore the lower and upper bounds for optimization for both cases were different for all parameters of the DAs. The known parameters were the kinematic excitation $y(\mathrm{t})$ and the mass $m=93 \mathrm{~kg}$. The optimization boundaries and results of the optimization for the seat with parallel connected DA are in Table 1.

After the parallel system was evaluated the system with DAs in series was optimized. The optimization bounds and results of the optimization for the seat with DAs connected in series are in Table 2.

Table 2. Suspension parameters of the seat with DAs in series

\begin{tabular}{|c|c|c|c|}
\hline \multirow[b]{2}{*}{ Parameters } & \multicolumn{2}{|c|}{ Bounds } & \multirow[b]{2}{*}{ Result } \\
\hline & Lower & Upper & \\
\hline$b$ & 500 & 1200 & 1200 \\
\hline$k$ & 3000 & 9600 & 3002 \\
\hline$m_{1}$ & 3 & 5 & 5 \\
\hline$b_{1}$ & 20 & 900 & 20,1 \\
\hline$k_{1}$ & 150 & 2500 & 1260 \\
\hline$m_{2}$ & 3 & 9 & 9 \\
\hline$b_{2}$ & 25 & 800 & 25,4 \\
\hline$k_{2}$ & 180 & 2400 & 1871 \\
\hline
\end{tabular}

From the optimized values of the searched parameters it is clear that the masses in both cases are almost the same.

On the other hand the change of the boundaries caused that the coefficients of damping $b_{\mathrm{i}}$ and spring stiffness $k_{\mathrm{i}}$ change vastly. In the case where the DAs were parallel the coefficient of one DA is almost $260 \mathrm{Ns} / \mathrm{m}$, the second coefficient is only $39.4 \mathrm{Ns} / \mathrm{m}$. The spring stiffness is 4 times different. This secured the different resonant frequencies of both DA, which reduced the vibration in a wider frequency range.

In the second case, where the DAs were in series the coefficients of damping $b_{\mathrm{i}}$ had low values. They reached the lower boundaries for both dampers. The difference in the spring stiffness $k_{\mathrm{i}}$ was only about smaller compared to the parallel DAs. In the case when the DAs are in series it is difficult to conclude if the DAs reduced the vibrations in a wider frequency range.

For better understanding of the effect of multiple DAs applied to the seat the displacements of the seat were evaluated. The main criterions for defining which configuration is better the maximal amplitudes of the displacements were considered and the second criterion was the effective value of displacements, which gives an overall result of the seat displacements.
Table 3. Suspension parameters of the seat without DAs

\begin{tabular}{|c|c|c|c|}
\hline & \multicolumn{3}{|c|}{ Bounds } \\
\hline Parameters & Lower & Upper & Result \\
\hline$b$ & 500 & 4000 & 3505 \\
\hline$k$ & 3000 & 9600 & 3191 \\
\hline
\end{tabular}

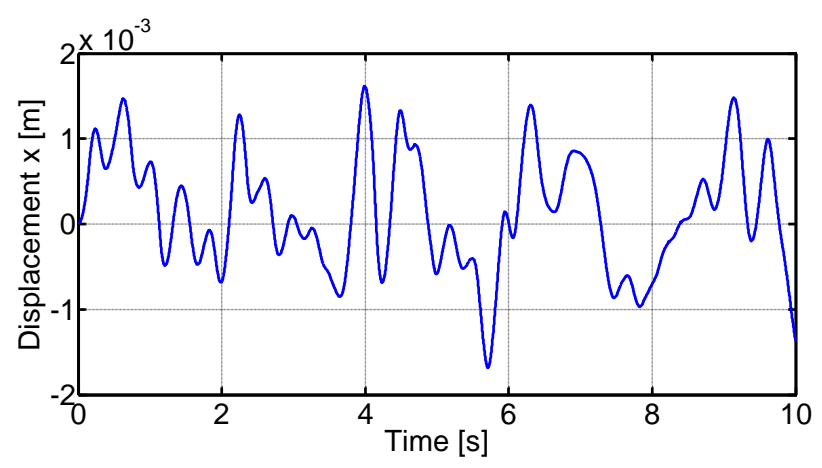

Figure 5. Seat displacement $x(\mathrm{t})$ without DA

For comparing the reduction of the displacements of the seat by applying DAs to the seat, as the first, the seat was calculated without any DAs. The optimized parameters of the seat without DAs are in Table 3. The time dependence of the seat displacements is for this case documented in Figure 5.

The effective values of displacements have to be evaluated. The effective value of displacements is formulated as

$$
d_{\text {effective }}=\sqrt{\frac{1}{T} \int d^{2}(t) d t},
$$

where

$T$ is the calculus time [s],

$d$ is the displacement [m].

The effective value of the seat displacements is noted in Table 4 together with the minimal and maximal values of the seat displacements.

Table 4. Seat displacements without DAs

\begin{tabular}{|c|c|c|}
\hline \multicolumn{3}{|c|}{ Displacements [m] } \\
\hline minimal & maximal & Effective value $[\mathrm{m}]$ \\
\hline$-1,7.10^{-3}$ & $1,6.10^{-3}$ & $7,1386.10^{-4}$ \\
\hline
\end{tabular}

After the seat displacements were evaluated the influence of the applied DAs was investigated. The seat displacements for both cases are documented in Figure 6.

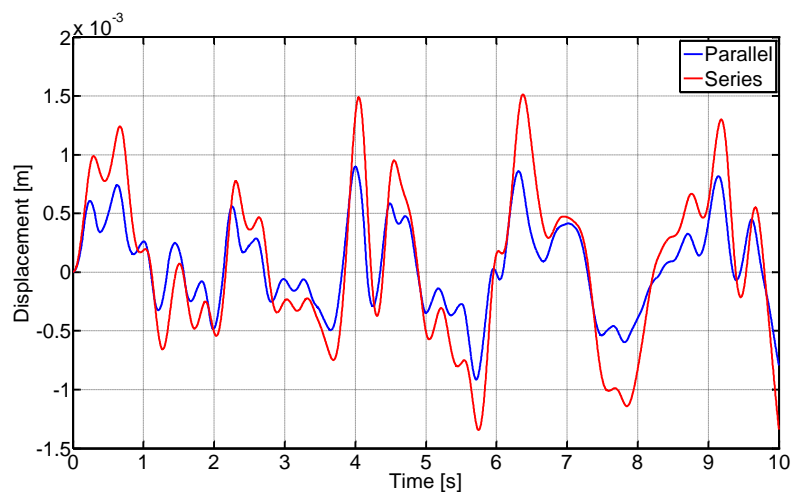

Figure 6 Seat displacements $x(t)$ with DA

From Figure 6 it is clear that the reduction of the seat displacements was achieved in both cases. As in the case 
of the seat without DA the minimal and maximal as well as the effective values of displacements were evaluated for both investigated cases. The results are shown in Table 5.

Table 5. Seat displacements with applied DA

\begin{tabular}{|c|c|c|c|}
\hline \multirow{2}{*}{ Configuration } & \multicolumn{3}{|c|}{ Displacements [m] } \\
\cline { 2 - 4 } & minimal & maximal & Effective value [m] \\
\hline parallel & $-0,81.10^{-3}$ & $0,83.10^{-3}$ & $3,8834.10^{-4}$ \\
\hline series & $-1,41.10^{-3}$ & $1,51.10^{-3}$ & $6,4927.10^{-4}$ \\
\hline
\end{tabular}

From the obtained results it is clear that both configurations of the DAs reduced the displacements of the seat compared to the seat without any DAs. The first criterion was the reduction of the minimal and maximal amplitudes. Comparing the seat without DAs and the seat with DAs in series the reduction of the minimal amplitude was for about $17 \%$. The maximal amplitude was reduced for $6 \%$. The effective value of the seat displacements was $9 \%$ smaller.

Comparing the second configuration with the seat without any DAs the reduction of the minimal amplitude of displacement was $52 \%$, and the maximal amplitude was reduced for $48 \%$. The effective value of displacement in this case was almost two times lower (46\% reduction).

Comparing both investigated cases of the seat with applied DAs the reduction of vibration was higher for the configuration when DAs were connected parallel. Comparing this both cases the configuration with parallel DA reduced the minimal amplitude of displacement for $42 \%$, the maximal amplitude for $45 \%$ and the effective value of displacement was $40 \%$ lower compared to the system with DAs in series.

\section{Conclusion}

From the obtained results it can be concluded that the application of multiple parallel DAs can vastly reduce the vibration of the suspended mass. It is caused by the fact that the DAs have different natural frequencies, thus they reduce the vibrations in a wider frequency range compared to a system without DAs or with a solo DA which is set for only one frequency.
The methodology for evaluating the seat and DA parameters by genetic algorithms has its advantages. The biggest advantage is ignoring the frequency analysis and analytic tuning of the DA. A big disadvantage can be the fact, that genetic algorithms are very sensitive to the set and range of the boundaries, therefore they have to be chosen correctly.

\section{Acknowledgement}

The research presented in this paper has been financially supported by projects VEGA 1/1205/12, VEGA 1/0937/12 and KEGA 054TUKE-4/2014.

\section{References}

[1] Segl'a, Š., Orečný, M., Trišović, N, Semiaktívne odpruženie sedačky s využitím dynamického absorbéra, In: DTDT 2013: Dynamika tuhých a deformovatelných těles 2013: sborník přednášek z 11. mezinárodní vědecké konference: 9.10. - 11.10. 2013: Ústí nad Labem. - Ústí nad Labem: Univerzita J. E. Purkyně, 2013 P. 1-8.

[2] Collete, Ch., Horodinca, M., Preumont, A., Rotational vibration absorber for mitigation of rail rutting corrugation, Vehicle System Dynamics, 47(6), 641-659, June 2009.

[3] Li, H.N., Ni, X.L., Optimization of non-uniformly distributed multiple tuned mass dampers. Journal of Sound and Vibration 308, 2007, 80-97.

[4] Sun, C. et al., Hardering Duffing Oscilator attenuation using a nonlinear TMD, a semi-active TMD and multiple TMD. Journal of Sound nad Vibration 332, 2013, 674-686.

[5] Eason, R.P. et al., Attenuation of linear oscilator using a nonlinear and semi-active tuned mass damper in series. Journal of Sound and Vibration 332, 2013, 154-166.

[6] Maciejewski, I., Meyer, L., Krzyzynski, T., Modelling and multicriteria optimisation of passive seat suspension vibr-isolating properties, Journal of Sound and Vibration, 324, 2009, 520-538.

[7] Ssegl'a, Š., Orečný, M., Trišović, N., Optimalizácia pasívneho odpruženia sedačky pracovného stroja. In: DTDT 2013: Dynamika tuhých a deformovatelných těles 2013: sborník přednášek z 11. mezinárodní vědecké konference: 9.10. - 11.10. 2013: Ústí nad Labem. - Ústí nad Labem: Univerzita J. E. Purkyně, 2013 P. 1-8.

[8] Segl'a, Š., Trišović, N., Modeling and Optimization of Passive Seat Suspension. American Journal of Mechanical Engineering, 7, 2013, 407-411. 